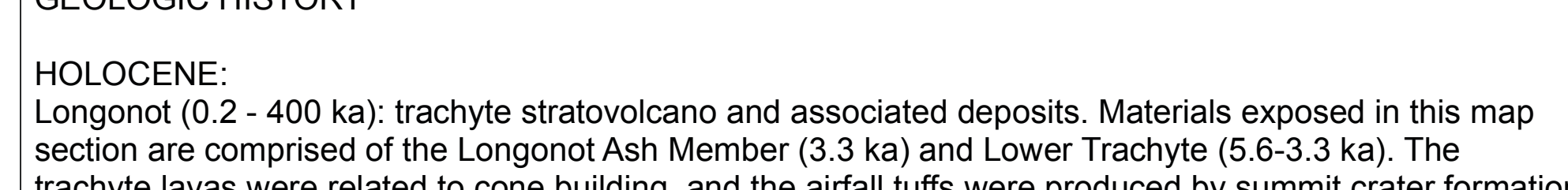

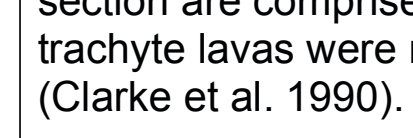

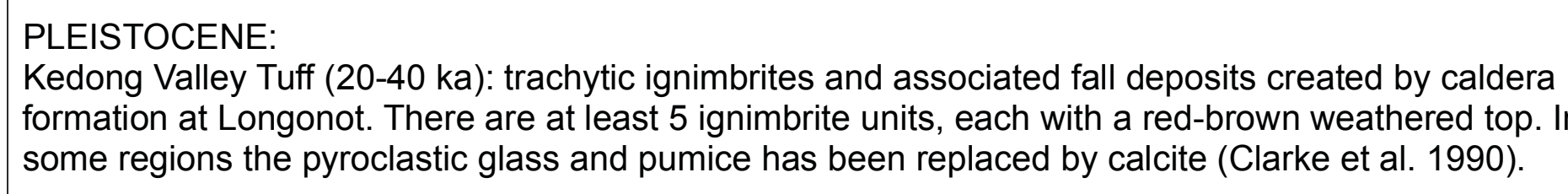

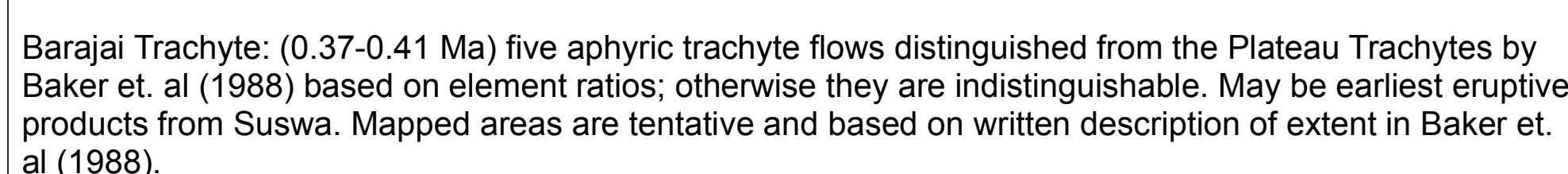

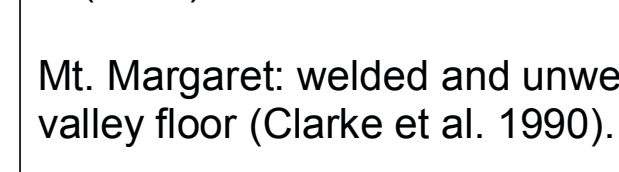

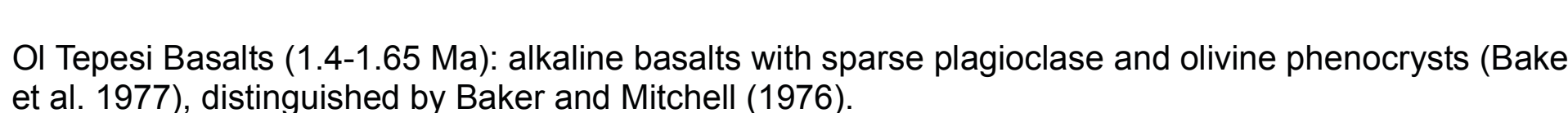

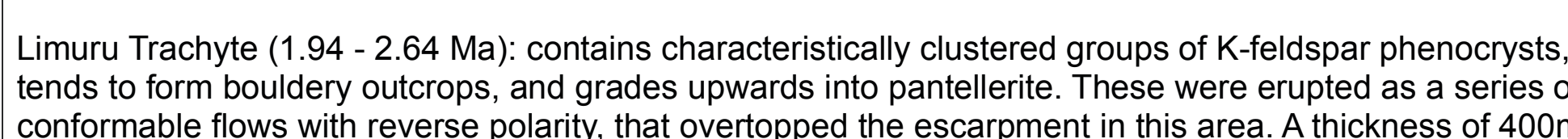

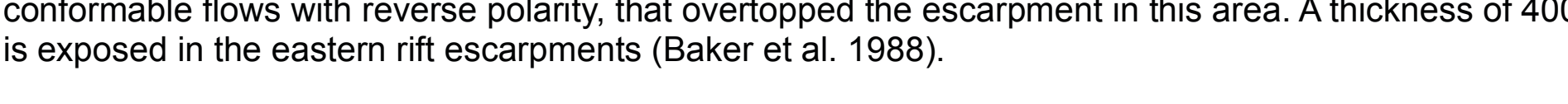

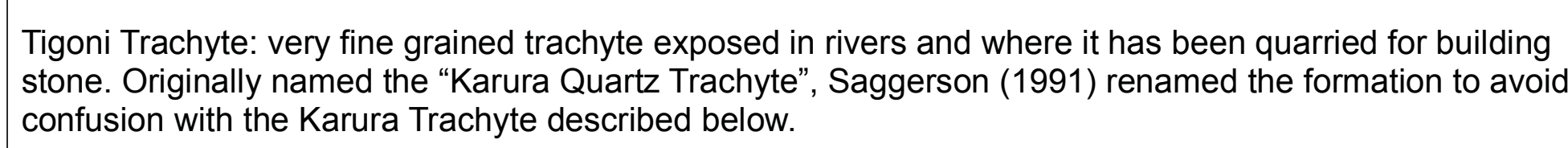

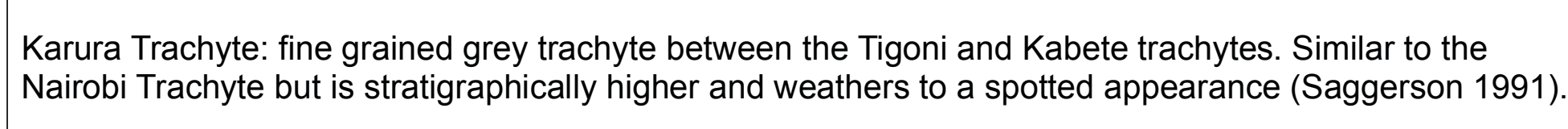

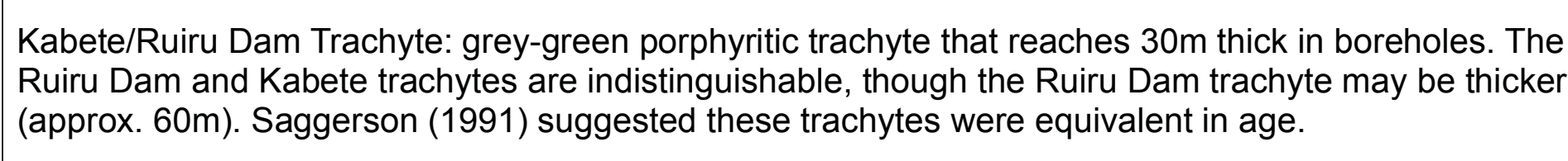

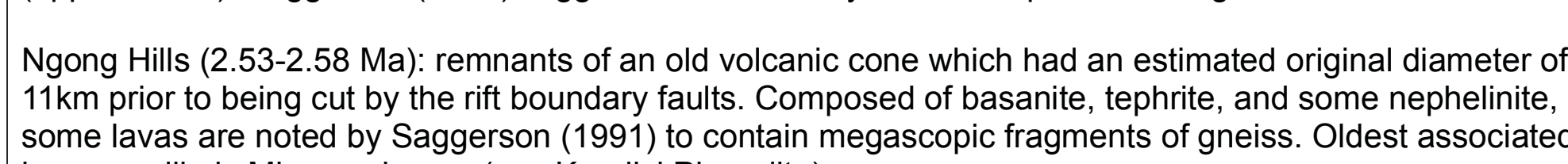
PLava are

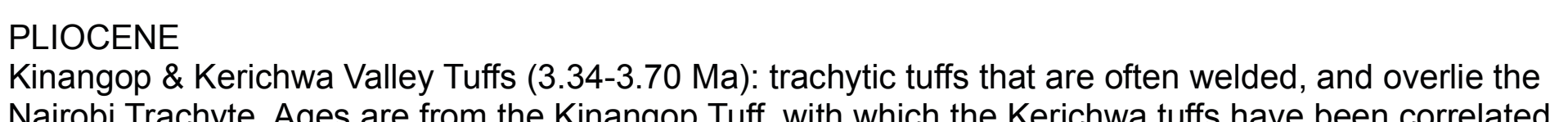

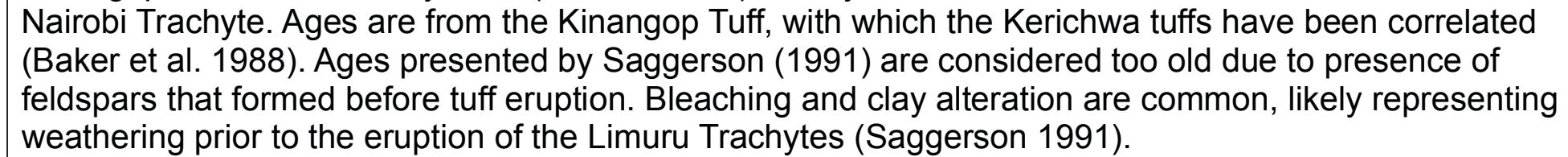

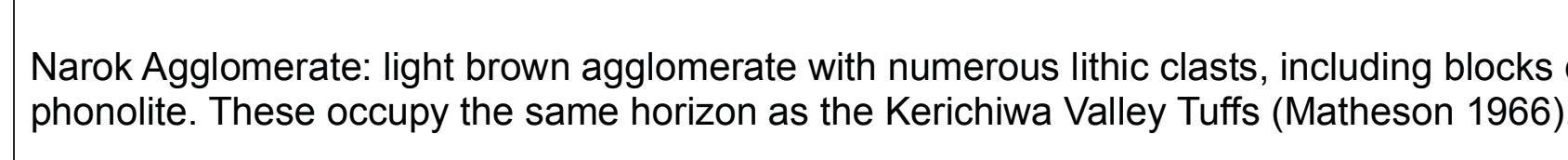

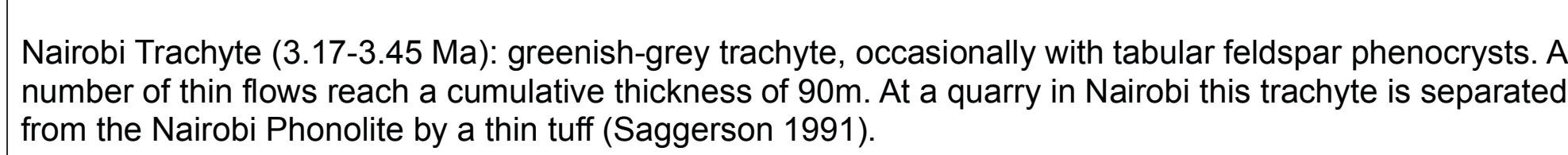

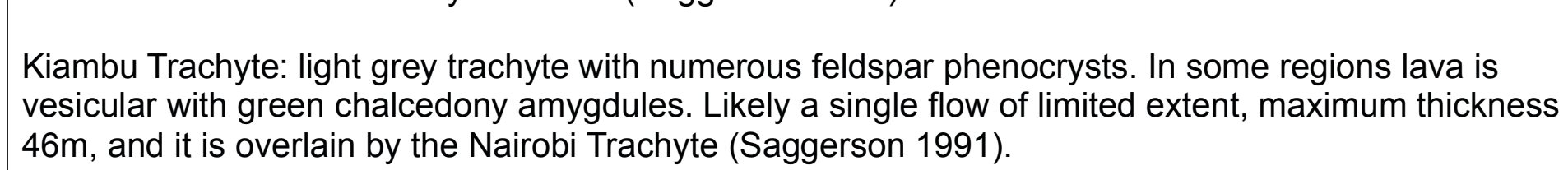

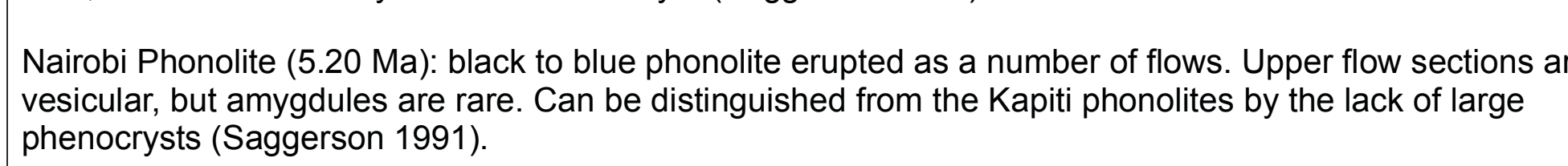

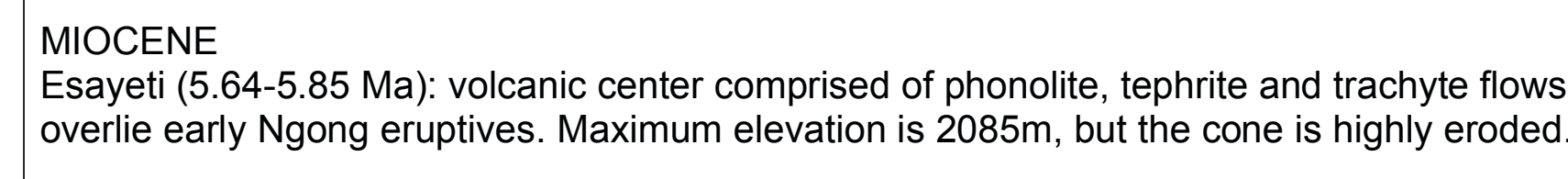

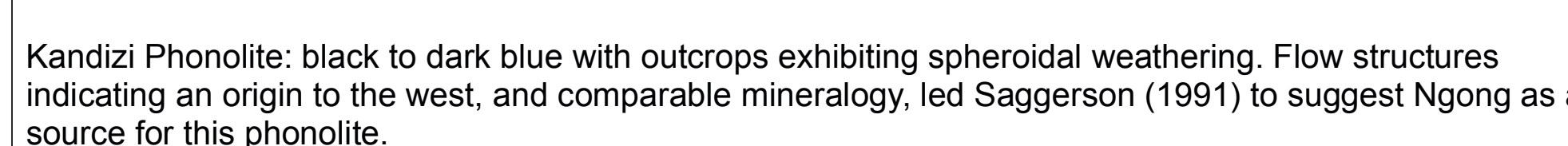

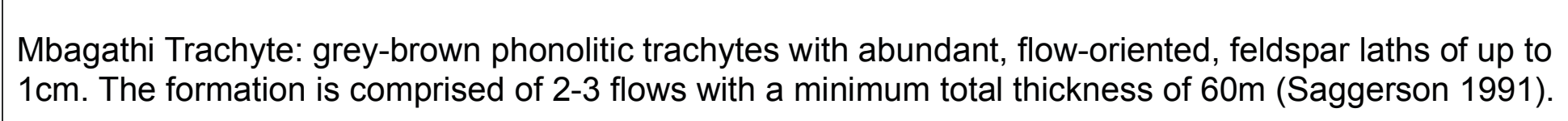

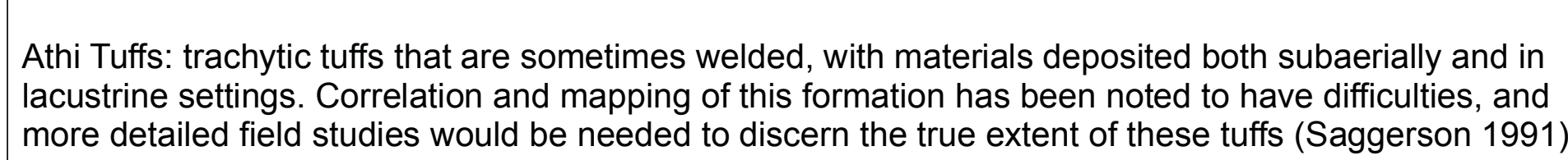

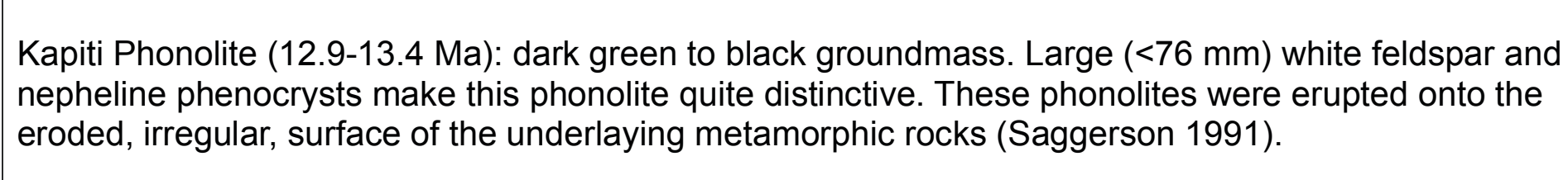
BAEEMENT SYSTEM:
Exposurusas are described

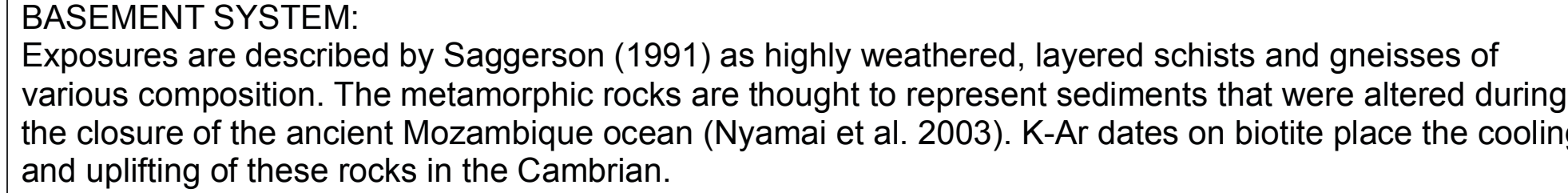
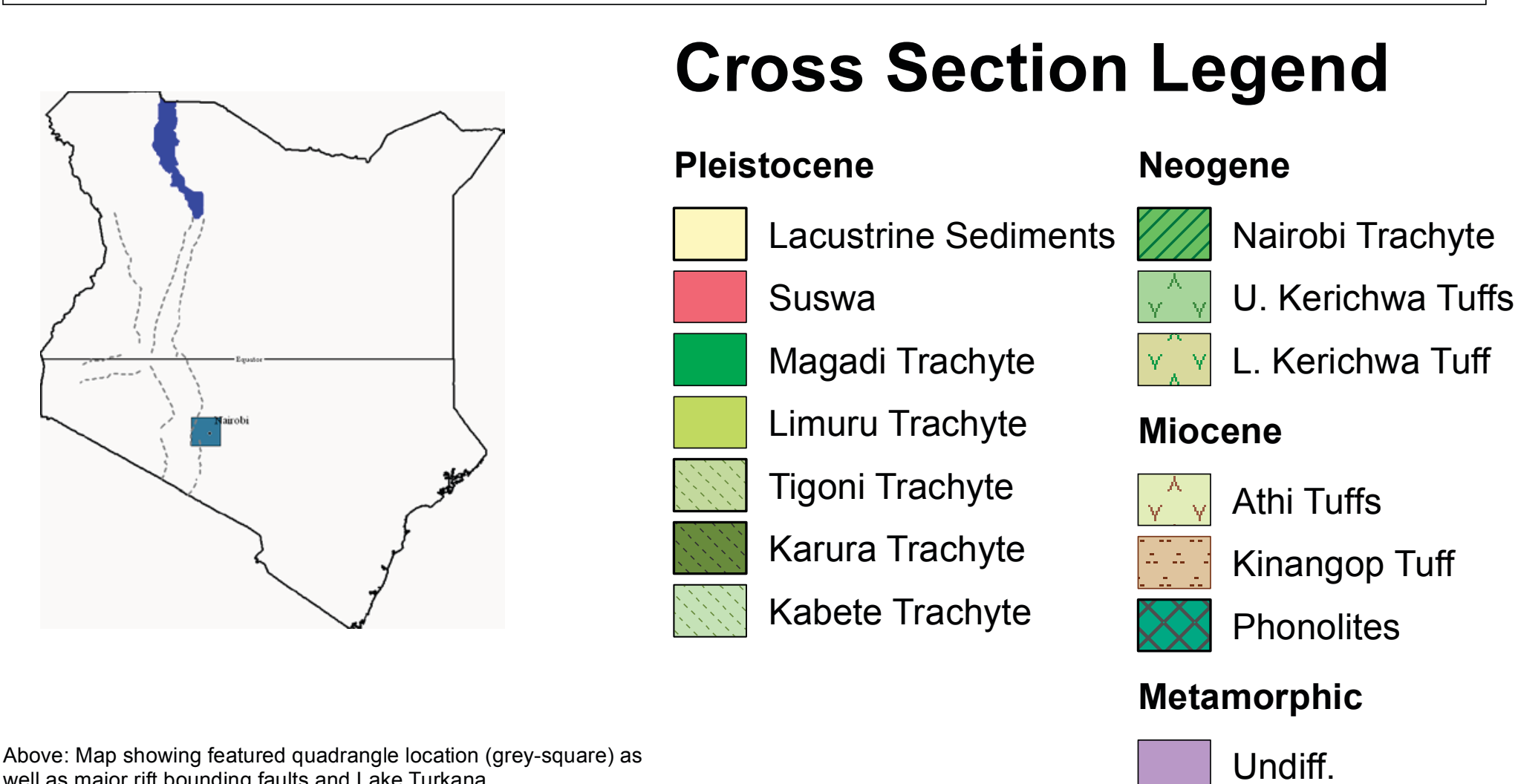

\section{Geology of the Nairobi Region, Kenya}

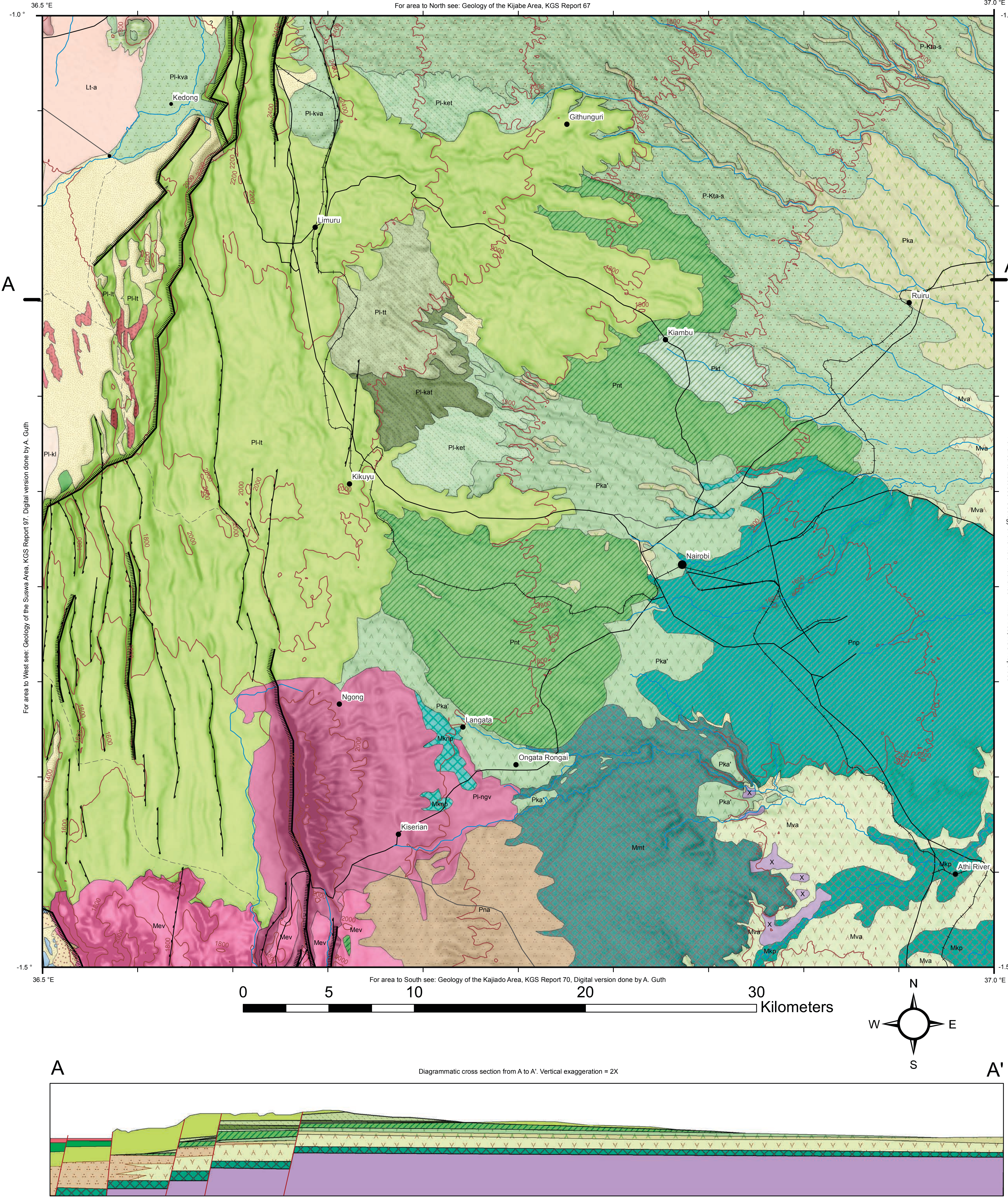

Legend

Sediments

․:. Alluvial fan

Kedong Lake Sediments

Holocene

Thom Tha

Prita Longonot ashes Karura Trachyle

Peistocene: Upper

rikixil Kedong Valley Tuff

Pleistocene: Ionian

Ppined Kabete Trachyte

[Fand Ngong Hills

Pliocene

Suswa shield trachytes

Prlocene Kinangop Tuff soils

Pikiaia Kinangop Tuff

$A^{\prime}$ -

- faults-smal

- City - Road-major

Town - Road-mador

- 200m-contor - raad-track

STRUCTURE
The metamor

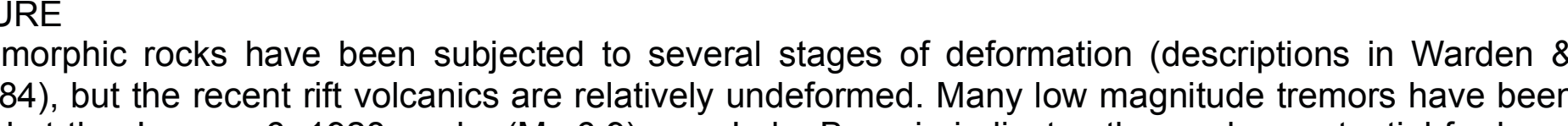

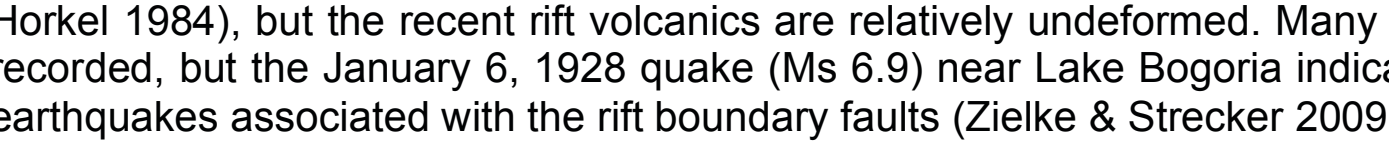

ALEONTOLOGY

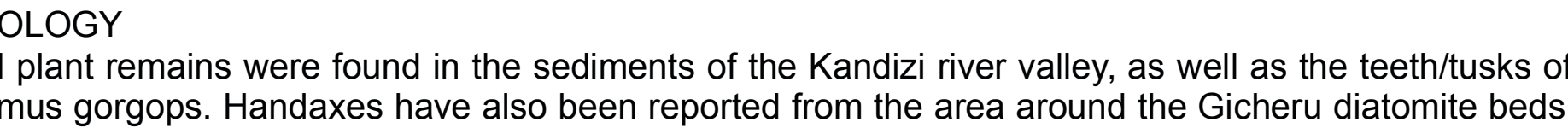

CONOMIC DEPOSITS

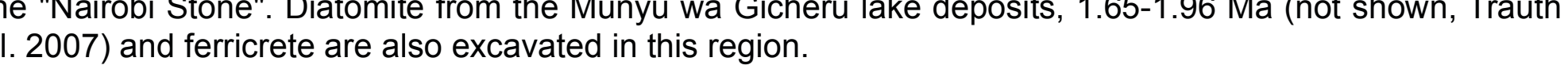

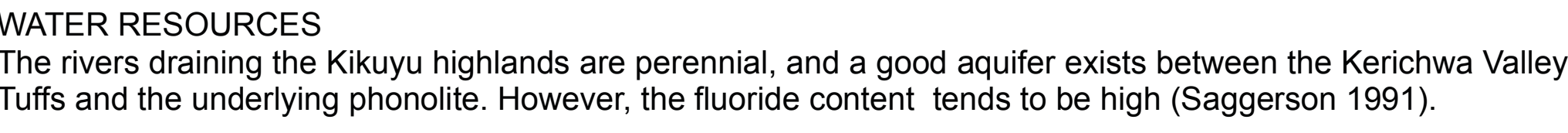

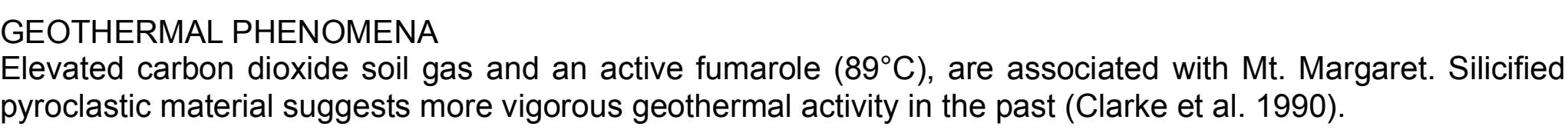
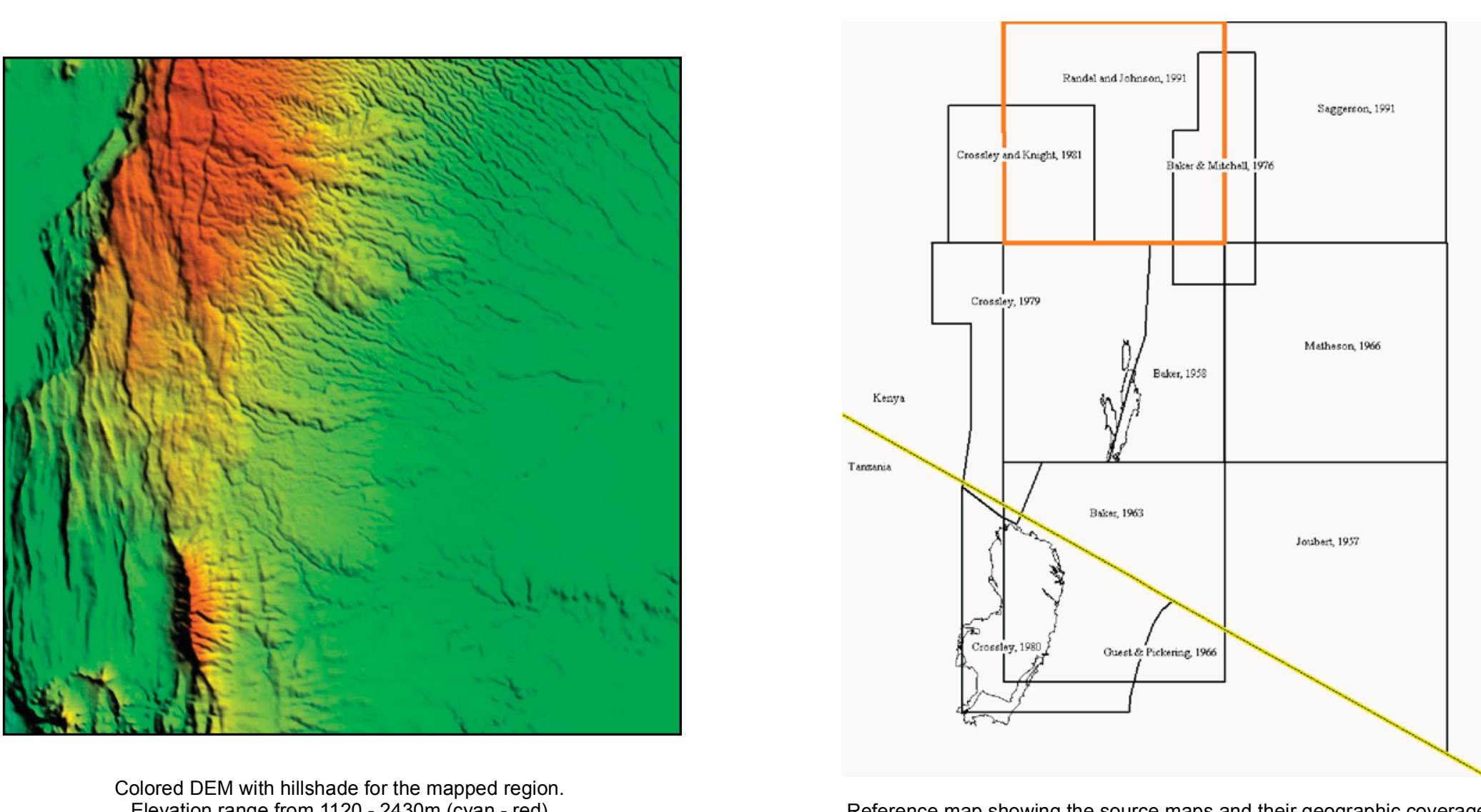

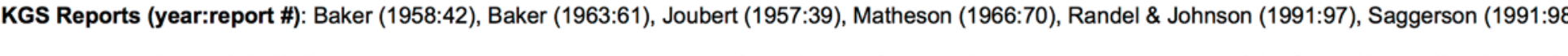

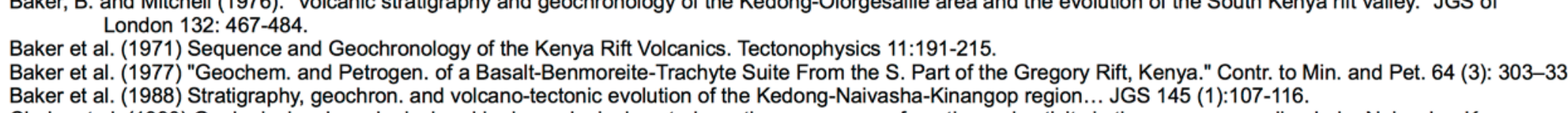

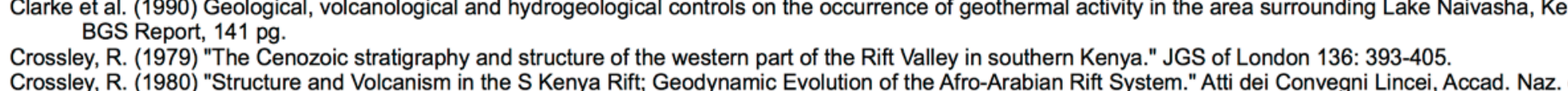

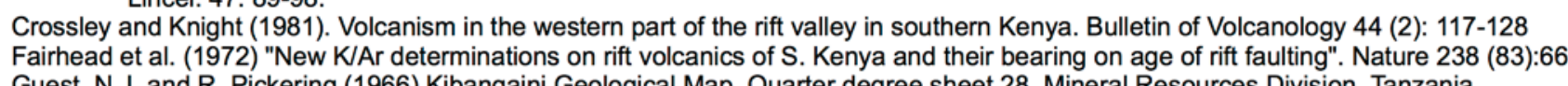

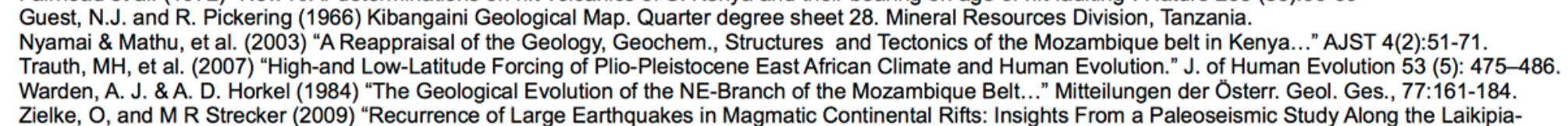

Geological Map of the Southern Kenya Rift

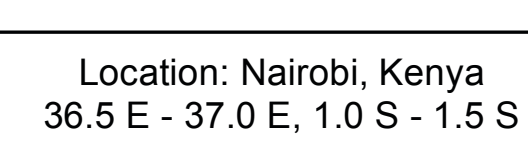
A. Guth, J. Wood (2013) 